\title{
Biocatalytic Conversion of Methane to Methanol as a Key Step for Development of Methane-Based Biorefineries
}

\author{
In Yeub Hwang, ${ }^{1}$ Seung Hwan Lee ${ }^{2}$, Yoo Seong Choi ${ }^{3}$, Si Jae Park ${ }^{4}$, Jeong Geol Na ${ }^{5}$, In Seop Chang ${ }^{6}$, \\ Choongik Kim ${ }^{7}$, Hyun Cheol Kim ${ }^{7}$, Yong Hwan Kim ${ }^{8}$, Jin Won Lee ${ }^{7 *}$, and Eun Yeol Lee ${ }^{1 *}$ \\ ${ }^{1}$ Department of Chemical Engineering, Kyung Hee University, Gyeonggi-do 446-701, Republic of Korea \\ ${ }^{2}$ Industrial Biochemicals Research Group, Research Center for Biobased Chemistry, Korea Research Institute of Chemical Technology, Daejeon \\ 305-600, Republic of Korea \\ ${ }^{3}$ Department of Chemical Engineering, Chungnam National University, Daejeon 305-764, Republic of Korea \\ ${ }^{4}$ Department of Environmental Engineering and Energy, Myongji University, Gyeonggido 449-728, Republic of Korea \\ ${ }^{5}$ Clean Fuel Department, Korea Institute of Energy Research, Daejeon 305-343, Republic of Korea \\ ${ }^{6}$ School of Environmental Science and Engineering, Gwangju Institute of Science and Technology, Gwangju 500-712, Republic of Korea \\ ${ }^{7}$ Department of Chemical and Biomolecular Engineering, Sogang University, Seoul 121-742, Republic of Korea \\ ${ }^{8}$ Department of Chemical Engineering, Kwangwoon University, Seoul 139-701, Republic of Korea
}

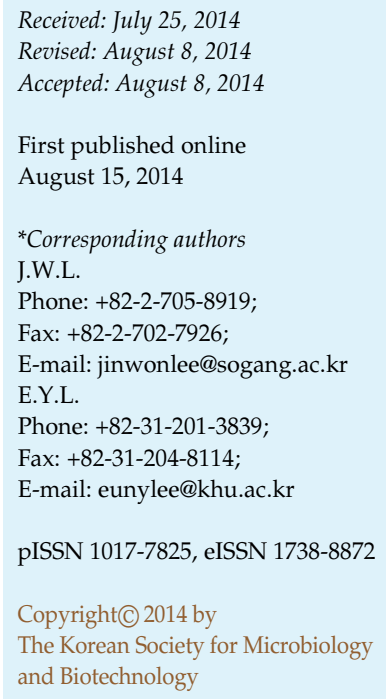

\begin{abstract}
Methane is considered as a next-generation carbon feedstock owing to the vast reserves of natural and shale gas. Methane can be converted to methanol by various methods, which in turn can be used as a starting chemical for the production of value-added chemicals using existing chemical conversion processes. Methane monooxygenase is the key enzyme that catalyzes the addition of oxygen to methane. Methanotrophic bacteria can transform methane to methanol by inhibiting methanol dehydrogenase. In this paper, we review the recent progress made on the biocatalytic conversion of methane to methanol as a key step for methane-based refinery systems and discuss future prospects for this technology.
\end{abstract}

Keywords: Methane, methane monooxygenase, methanotrophs, methanol, natural gas, shale gas

\section{Introduction}

Methane is the primary component in natural and shale gas, comprising up to $90 \%$ of the total abundance. The world reserves of natural gas and shale gas have been estimated as being more than 6,614 [33] and 7,299 [26] trillion cubic feet, respectively. Thus, methane is considered as a next-generation carbon feedstock. In addition, methane constitutes more than $50 \%$ of the biogas generated from anaerobic digestion processes and landfill sites [16]. On the other hand, methane has attracted a great deal of attention from environmental scientists because it is the second most abundant greenhouse gas after carbon dioxide and 21 times more harmful [51].

At present, methane has very limited use as a simple combustion fuel. Accordingly, there are significant needs to efficiently utilize methane from natural and shale gas and add value to methane. Indeed, compared with methane, methanol can be more readily used as a starting chemical, as well as a fuel in gasoline blending [48]. The energy density of methanol $(15.8 \mathrm{MJ} / \mathrm{l})$ is higher than that of methane $\left(38.1 \times 10^{-3} \mathrm{MJ} / \mathrm{l}\right)$. In addition, the market demand for methanol as a carbon feedstock is growing because it can be converted to value-added derivatives such as 
methyl-tert-butyl ether and dimethyl ether [39]. The roles of various methanol-based chemical processes such as methanol-to-propylene and methanol-to-olefin conversion are also becoming significant [41].

Methane can be converted to methanol using indirect two-step methods. In this process, methane is first transformed to a syngas of $\mathrm{CO}$ and $\mathrm{H}_{2}$ using a reforming process, which is followed by transformation to methanol using metal catalysts. However, the conversion of methane and water to carbon monoxide and hydrogen in this way is an energy-intensive process that requires high temperatures $\left(>900^{\circ} \mathrm{C}\right.$ ) and costly equipment, accounting for approximately $60 \%$ of the total capital cost of the reaction process $[15,35$, 46]. In addition, this reaction process has a low overall conversion rate of less than $25 \%$ and selectivity less than $70 \%[2,32,42]$. Thus, the indirect conversion of methane to methanol is associated with a number of problems, including low energy efficiency and high capital cost [58].

Methanol can also be produced directly from methane by biological methods. Importantly, the bioconversion of methane to methanol is associated with low energy consumption, high conversion, high selectivity, and low capital costs compared with chemical methods, since it is carried out by methane monooxygenase (MMO) enzyme or methanotrophic cells under mild conditions [8]. MMO activates the stable $\mathrm{C}-\mathrm{H}$ bond of methane under ambient conditions, whereas methanotrophs express $\mathrm{MMO}$ for methane oxidation and utilize methane as their sole carbon and energy source under aerobic conditions. However, methanotrophs grow slowly, and thus the production of methanol from whole cells of methanotrophs is also low [11]. Because methanotrophs utilize methanol as both carbon and energy sources, one disadvantage of cell-based methane-to-methanol conversion is that the methanol is further metabolized to formaldehyde, formate, and carbon dioxide by methanol dehydrogenase, formaldehyde dehydrogenase, and formate dehydrogenase, respectively [59]. Thus, a high volumetric production of methanol by methanotrophs is currently difficult to achieve.

Methane-to-methanol conversion is attracting considerable attention owing to the abundant reserves of methane and the potential for utilization of methane as an alternative chemical feedstock for the production of value-added chemicals. Bioconversion may be a good choice for methaneto-methanol conversion, because bioconversion can be accomplished in an energy-efficient and environmentally benign manner. Herein, we review the recent progress on the biocatalytic conversion of methane to methanol using MMO and methanotrophs as biocatalysts and discuss the biotechnological potential of methane-to-methanol bioconversion.

\section{Methane-to-Methanol Bioconversion by Methane Monooxygenase}

Methane is chemically very stable owing to the presence of $\mathrm{C}-\mathrm{H}$ bonds $[5,18,50]$, which require $438.8 \mathrm{~kJ} / \mathrm{mol}$ to break [40]. MMO efficiently converts methane to methanol in biological systems [37] by splitting molecular oxygen and incorporating one atom of oxygen into methane. There are two classes of MMOs, namely, soluble MMO (sMMO) and membrane-associated $\mathrm{MMO}$, the latter of which is also referred to as particulate MMO (pMMO). Although both sMMO and pMMO catalyze methane oxidation, they exhibit significantly different catalytic characteristics, including different enzyme stabilities, specific activities,
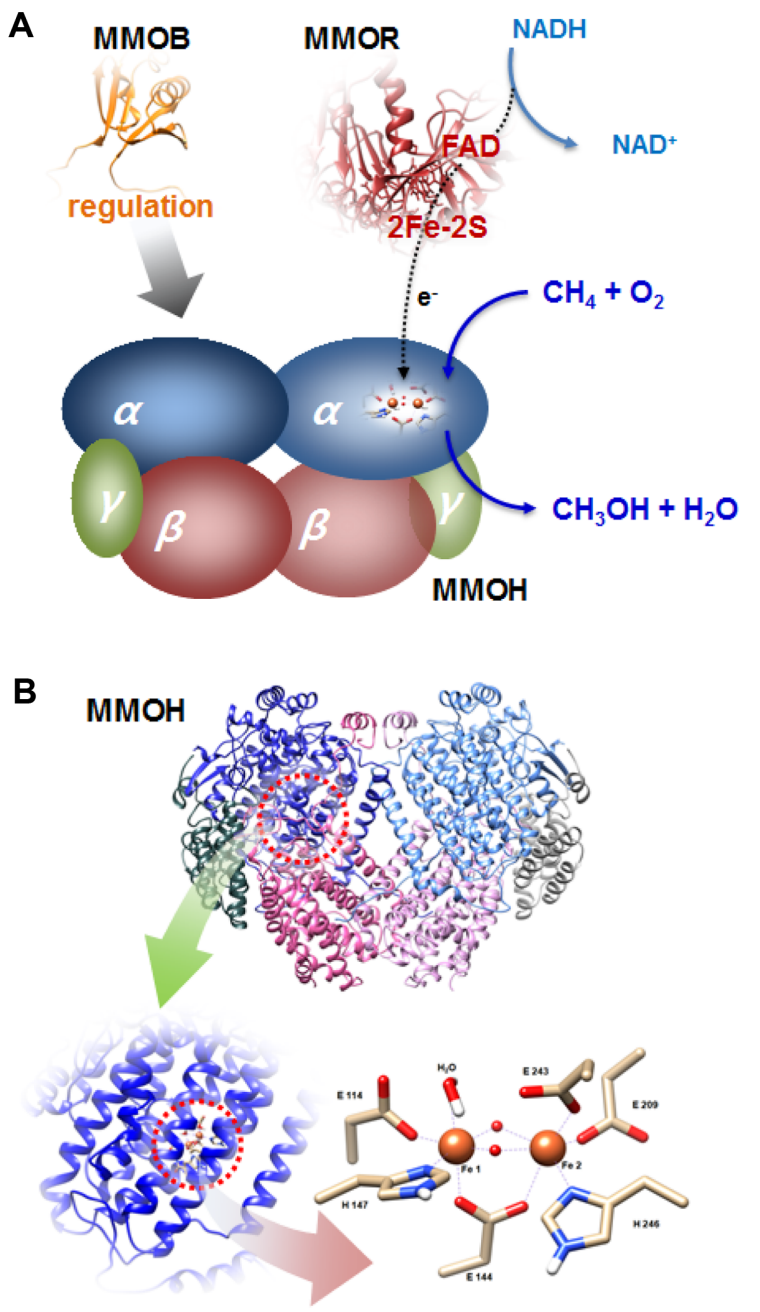

Fig. 1. Structural overview of Methylococcus capsulatus (Bath) soluble methane monooxygenase consisting of three subunits (A) and the homodimeric structure of hydroxylase containing a di-iron center (B) (modified from Friedle et al. [13]). 
and susceptibilities to inhibitors. For example, in terms of reducing power for the reaction, $\mathrm{SMMO}$ has a strict requirement for nicotinamide adenine dinucleotide (NADH), whereas $\mathrm{pMMO}$ can utilize the reducing power generated by formaldehyde dehydrogenase (FalDH) [52, 60]. The active sites of sMMO and pMMO also contain different metal ions, namely, iron and copper, respectively. pMMO is expressed under a high copper concentration [4, 30, 38, 49].

The catalytic mechanism of sMMO isolated from Methylococcus capsulatus (Bath) has been studied extensively. sMMO consists of three subunits with hydroxylase $(\mathrm{MMOH}, 251 \mathrm{kDa})$, reductase $(\mathrm{MMOR}, 38.6 \mathrm{kDa})$, and regulatory functions (MMOB, $15.9 \mathrm{kDa}$ ) (Fig. 1A) [29]. On the other hand, $\mathrm{MMOH}$ is a homodimeric protein consisting of two sets of $\alpha, \beta$, and $\gamma$ subunits containing a di-iron site, which is the primary domain responsible for catalyzing the conversion of methane with oxygen to methanol (Fig. 1B). MMOR contains a bound flavin adenine dinucleotide (FAD) and a [2Fe-2S]-ferredoxin (Fd) cofactor, which play key roles in the activation of $\mathrm{MMOH}$ by transferring reducing power to $\mathrm{MMOH}$ using NADH. MMOB is known to regulate the structure and reactivity of the non-heme diiron site of $\mathrm{MMOH}[13,45,47]$. In order to activate molecular oxygen, the di-iron center in $\mathrm{MMOH}$ undergoes cyclical changes, such as with intermediate $\mathrm{P}$ and intermediate $\mathrm{Q}$ and various states of diferrous, peroxo, diferryl, and diferric iron (Fig. 2). With respect to diferrous $\mathrm{MMOH}$ in reduced form, the di-iron centers react with molecular oxygen to form a peroxide species, intermediate

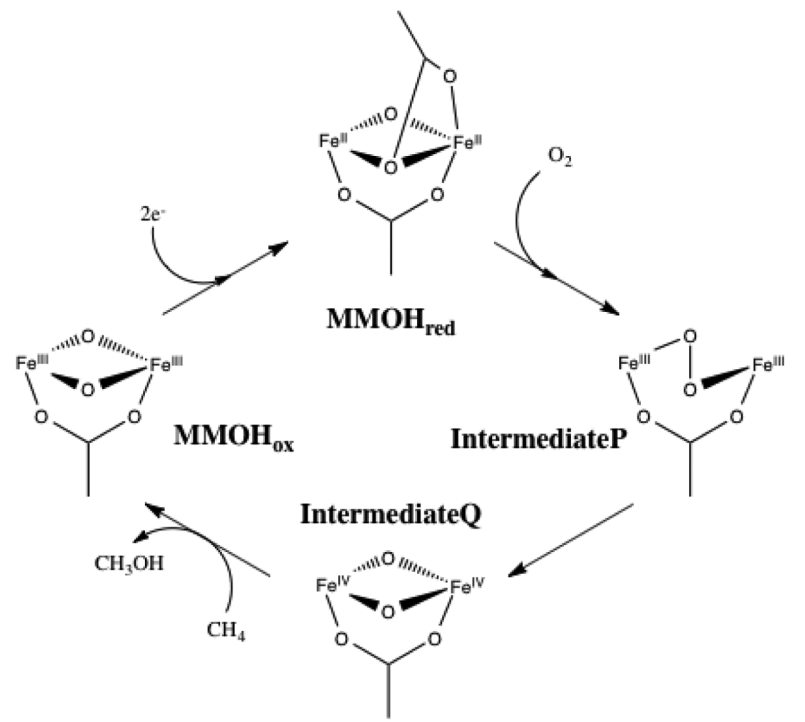

Fig. 2. Proposed catalytic mechanism of soluble methane monooxygenase (modified from Friedle et al. [13]).
$\mathrm{P}$. Intermediate $\mathrm{P}$ can then be converted to intermediate $\mathrm{Q}$, which contains an $\mathrm{Fe}^{\mathrm{IV}}$ center. Intermediate $\mathrm{Q}$ in turn abstracts hydrogen from methane to form $\mathrm{QH}$ and a free methyl radical, suggesting a radical mechanism. Methanol is eliminated immediately after transferring the $\mathrm{OH}$ group to the free radical, resulting in regeneration of the catalyst. In order to convert methane to methanol by sMMO, reducing power in the form of $\mathrm{NADH}$ is required to activate molecular oxygen [31].

Most methanotrophs constitutively express pMMO, which is the membrane-integrated form of MMO that is expressed in the presence of high concentrations of copper. As described above, pMMO comprises three subunits;
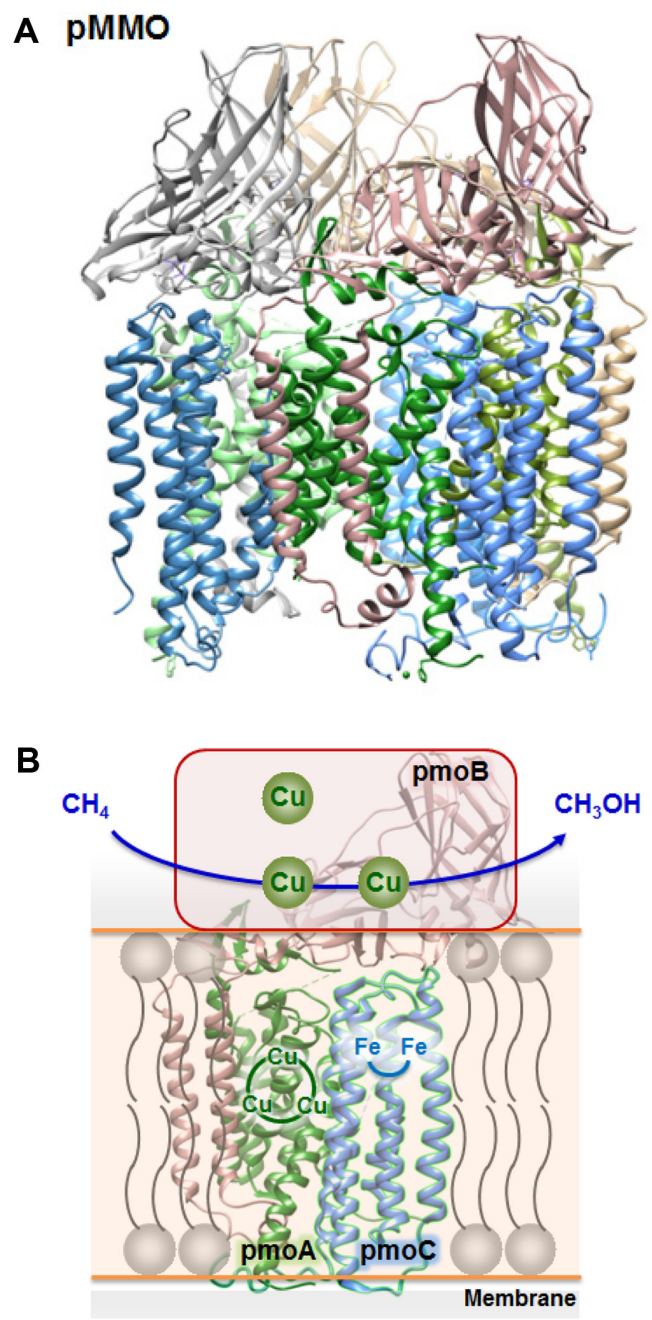

Fig. 3. Structural overview of the particulate methane monooxygenase (pMMO) (A) and the tri-copper cluster and the di-iron cluster in the intermembrane pmoA and pmoC subunits of the enzyme (B) (modified from Bollinger [6] and Culpepper and Rosenzweig [9]). 

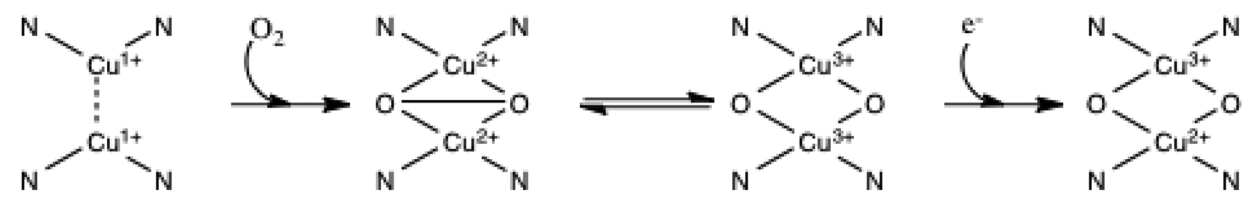

Fig. 4. Proposed catalytic mechanism of particulate methane monooxygenase (modified from Balasubramanian and Rosenzweig [4]).

namely, pmoA, pmoB, and pmoC. pMMO has a trimeric structure in an $\alpha 3 \beta 3 \gamma 3$ polypeptide arrangement (Fig. 3) [6, 9, 30]. The pmoA and pmoC subunits exist in the membrane in a helical structure. In contrast, pmoB has two transmembrane helices and a long loop region linked by a $\beta$-barrel motif. This soluble domain forms a hole for substrate entry and product exit and plays a key role in catalysis [17]. Structural analysis of pMMO from $M$. capsulatus has revealed that the active site comprises a mononuclear copper site (coordinated by His 48 and His 72), a dinuclear copper site (coordinated by His 33, His 137, and His 139), and zinc to facilitate various oxidation states to activate $\mathrm{O}_{2}$ [9]. Sequential formation of $\mathrm{Cu}(\mathrm{I}) \mathrm{Cu}(\mathrm{I})$, peroxo $\mathrm{Cu}(\mathrm{II}) \mathrm{Cu}(\mathrm{II})$, bis( $\mu$-oxo) $\mathrm{Cu}(\mathrm{III}) \mathrm{Cu}(\mathrm{III})$, and bis $(\mu-$ oxo) $\mathrm{Cu}(\mathrm{III}) \mathrm{Cu}(\mathrm{II})$ has been proposed for molecular oxygen activation by pMMO (Fig. 4) [61].

Despite significant progress on the analysis of the structure and function of sMMO and $\mathrm{pMMO}$, biotechnological application of isolated MMO enzymes remains limited owing to an inability to express functional protein in Escherichia coli. Furthermore, the isolation of significant quantities of functional sMMO and pMMO from methanotrophs is also somewhat difficult. However, in order to achieve enzyme-based methane-to-methanol bioconversion on a biotechnological scale, the functional expression and isolation problems need to be overcome, in addition to the development of an appropriate in vitro reducing power regeneration system.

\section{Methane-to-Methanol Bioconversion by Methanotrophs}

Methanotrophs are bacteria that utilize methane as their sole source of carbon for growth and are capable of activating stable $\mathrm{C}-\mathrm{H}$ bonds using $\mathrm{MMO}$ under ambient conditions [40]. Methanotrophs have recently attracted a great deal of attention from the field of biodegradation, specifically with regard to a wide range of priority pollutants, including trichloroethylene, through co-metabolic reactions catalyzed by MMO [20, 27]. In general, methanotrophs can be classified into three groups based on physiology (Fig. 5). Gammaproteobacterial methanotrophs are Type I

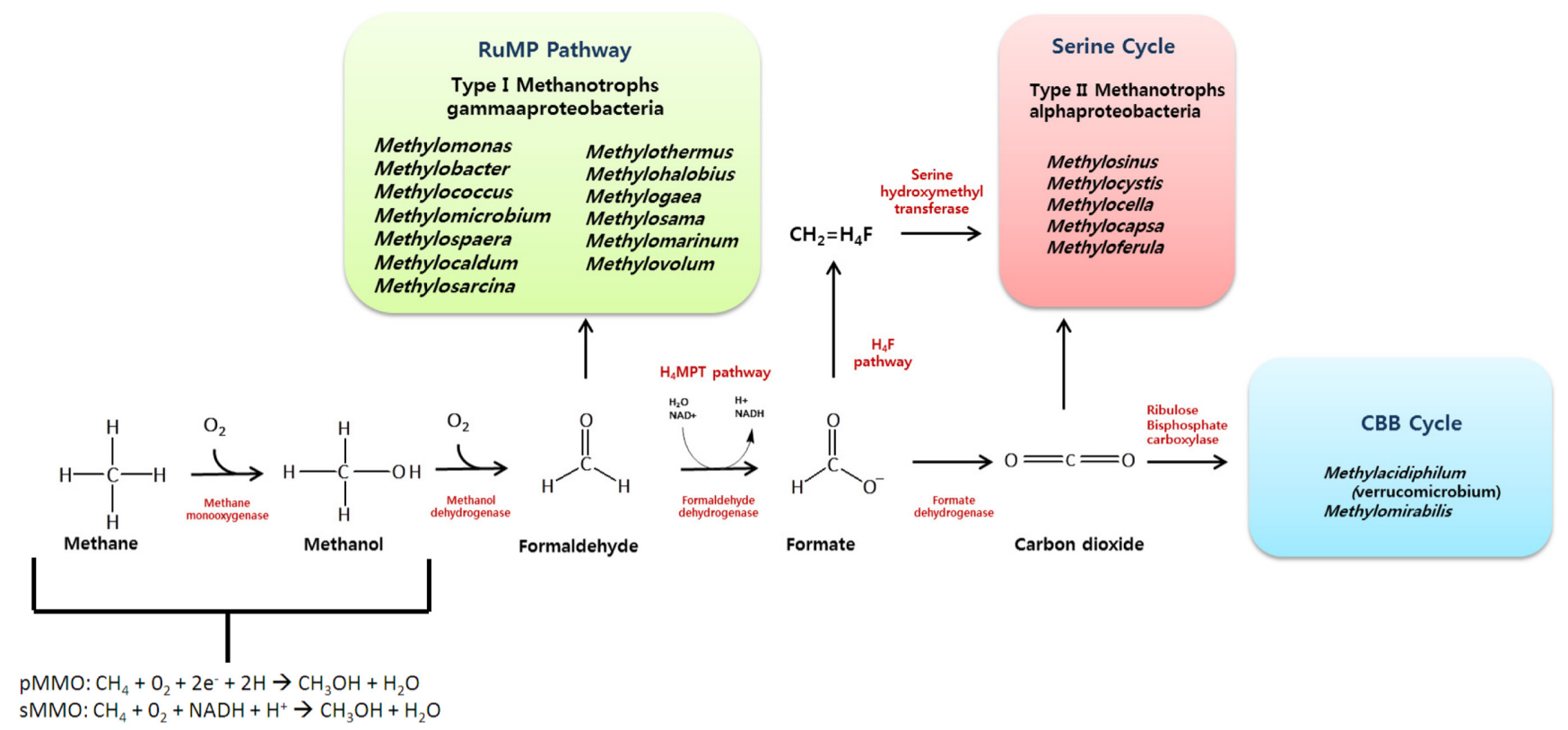

Fig. 5. Classification of methanotrophs based on physiology (modified from the Methanotrophs Consortium website, 2014). 
methanotrophs and utilize the ribulose monophosphate (RuMP) cycle for carbon assimilation. This group comprises the genera Methylococcus and includes M. capsulatus and Methylomonas. The RuMP cycle allows for the synthesis of key intermediates for central metabolic routes from formaldehyde (Fig. 6). In this system, carbon is fixed into the cell biomass via aldol condensation of formaldehyde with D-ribulose-5-phosphate to form 3-hexulose 6-phosphate. Type II methanotrophs are Alphaproteobacteria and comprise the Methylosinus genera including M. trichosporium. Type II methanotrophs use the serine cycle for carbon assimilation and have a functional TCA cycle. Specifically, 3-phosphoglycerate is synthesized from formaldehyde and $\mathrm{CO}_{2}$ via the serine cycle. A novel Type III class of thermoacidophilic aerobic methanotrophs called Verrucomicrobia was recently identified and was also shown to assimilate $\mathrm{CO}_{2}$ using the Calvin Benson Bassham cycle [12, 43]. Importantly, Methylacidiphilum fumariolicum has the potential to be cultivated using a mixture of methane and $\mathrm{CO}_{2}$ to improve cell growth and product yield [23].

In terms of methane conversion to methanol, many methanotrophs, including Methylosinus trichosporium OB3b and Methylococcus capsulatus (Bath), have been employed. Methanotrophs can convert methane to carbon dioxide through four successive metabolic steps, consisting of methane to methanol, methanol to formaldehyde, formaldehyde to formate, and finally formate to carbon dioxide (Fig. 5) [7, $10,56,57]$. The classical periplasmic MxaF-type methanol dehydrogenase is a pyrroloquinoline quinone (PQQ)dependent enzyme composed of an $\alpha 2 \beta 2$ tetramer [1]. Methanol dehydrogenase (MDH)-catalyzed oxidation of methanol to formaldehyde is coupled to a periplasmic mono-c-type cytochrome and cytochrome $c_{\mathrm{L}}$ in obligate aerobic methanotrophs such as $M$. capsulatus [57]. In order to accumulate methanol, MDH should be inhibited. Therefore, the functional expression of highly active MMO and the accumulation of methanol by inhibition of $\mathrm{MDH}$ are essential features of methanotrophic conversion of methane with high methanol productivity under aerobic conditions [59].

The selectivity and conversion of methane to methanol by methanotrophs are very high owing to the excellent

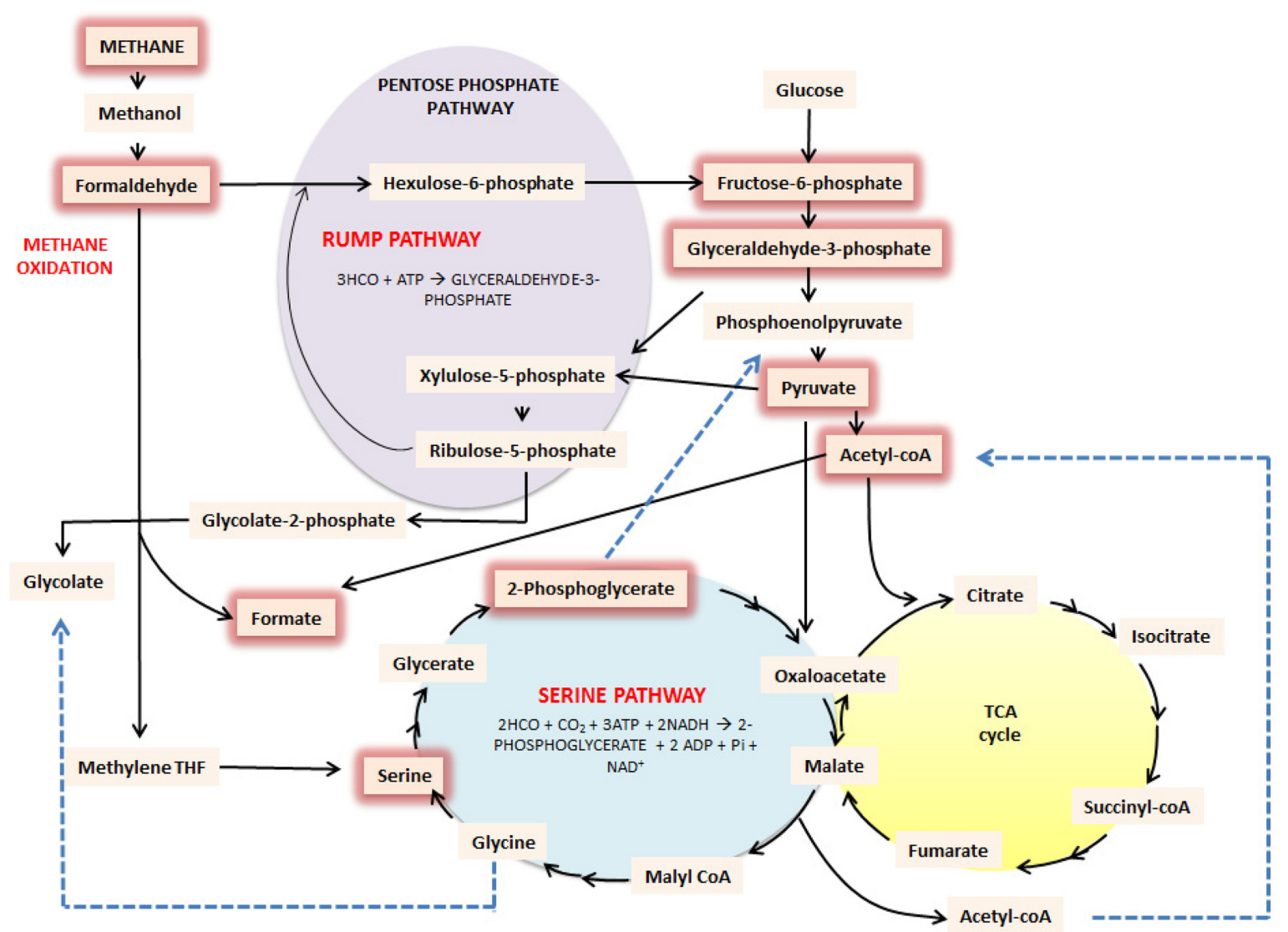

Fig. 6. Simplified methane metabolic pathways of the ribulose monophosphate (RuMP) cycle and serine cycle in methanotrophs. Major enzymes and metabolic intermediates are presented in the metabolic pathways (modified from Chistoserdova and Lidstrom [7]). 
performance of sMMO and pMMO. The expression pattern and abundance of MMO are highly dependent on the copper concentration of the medium. When copper is limited, sMMO is present in the cytosol, whereas pMMO is primarily expressed in the presence of high levels of copper [17, 34, 44, 49]. In addition, sMMO and pMMO differ from each other with respect to substrate and inhibitor specificities, enzyme stability, relative activities, and reducing power requirements and generation. $\mathrm{pMMO}$ has a higher affinity for methane compared with sMMO [31]. In terms of reducing power utilization, sMMO utilizes $\mathrm{NADH}$, whereas pMMO uses electrons from ubiquinolbased electron transfer systems associated with the FalDHcatalyzed reaction of formaldehyde to formate [10]. For increased methanol productivity in sMMO-catalyzed methane oxidation, exogenous NADH should be supplied because one mole of NADH is stoichiometrically required for the oxidation of one mole of methane to methanol. In methanotroph-mediated metabolism, NADH is generated when FalDH and FDH convert formaldehyde to formate and formate to carbon dioxide, respectively. Thus, when the activity of MDH is fully inhibited, NADH cannot be generated. Formate is commonly supplied as a co-substrate for methanotrophic methanol production with $\mathrm{MDH}$ inhibition, because one mole of formate oxidation by formate dehydrogenase generates one mole of NADH from NAD [22, 62].

Methanotrophic methane-to-methanol conversion on the biotechnological scale has been investigated primarily using M. trichosporium OB3b, which can be cultured on methane in Higgins nitrate mineral salt medium containing $5 \mu \mathrm{M} \mathrm{Cu}^{2+}$ to express pMMO [36, 55]. However, in order to prevent further oxidation of methanol, the MDH activity must be efficiently inhibited. Various MDH inhibitors, including metal chelating agents such as EDTA, cyclopropane, cyclopropanol, dithiothreitol, phenylhydrazine, $\mathrm{NaCl}$, iodoacetate, $\mathrm{MgCl}_{2}$, and high concentrations of phosphate, have been employed to prevent methanol conversion to formaldehyde. Indeed, the presence of chelating agents such as EDTA in media significantly inhibits the activities of methanol oxidase and MDH [59]. When cyclopropanol is used for the irreversible inhibition of methanol dehydrogenase, M. trichosporium OB3b could produce methanol with a production efficiency of $61 \%$ and a methanol concentration of $152 \mathrm{mmol} / \mathrm{g}$ dry cell for $100 \mathrm{~h}$ [54]. Furuto et al. [14] also employed cyclopropanol to inhibit methanol dehydrogenase activity, obtaining $6 \mathrm{mM}$ methanol using a semi-continuous process.

$\mathrm{NaCl}(200 \mathrm{mM})$ has also been successfully employed for
$\mathrm{MDH}$ inhibition in $M$. trichosporium OB3b to achieve methane-to-methanol conversion, resulting in $7.7 \mathrm{mM}$ methanol from $0.6 \mathrm{mg}$ dry cells $/ \mathrm{ml}$ at $25^{\circ} \mathrm{C}$ in $12.9 \mathrm{mM}$ phosphate buffer $(\mathrm{pH} 7)$ containing $20 \mathrm{mM}$ sodium formate

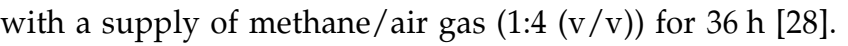
However, when $\mathrm{NaCl}$ was used for MDH inhibition in M. trichosporium OB3b, the activities of both pMMO and $\mathrm{MDH}$ were inhibited, although the extent of enzyme inhibition for MDH was much greater than that of $\mathrm{pMMO}$, thereby allowing for methanol accumulation.

A novel compulsory circulation diffusion system was developed for the cultivation of $M$. trichosporium OB3b under optimal conditions $\left(5 \mu \mathrm{M} \mathrm{CuSO}_{4}, \mathrm{pH} 7.0,30^{\circ} \mathrm{C}\right)$ with a supply of methane/air $(1: 1(\mathrm{v} / \mathrm{v}))$ prepared in a tightly sealed gas reservoir [25]. A cell concentration of $0.6 \mathrm{mg}$ dry cells $/ \mathrm{ml}$ in $10 \mathrm{mM}$ phosphate buffer ( $\mathrm{pH} 7.0$ ) (working volume of $100 \mathrm{ml}$ in a $500 \mathrm{ml}$ flask) was used for methaneto-methanol conversion in batch and repeated-batch modes. In the presence of $100 \mathrm{mM} \mathrm{NaCl}$ and $1 \mathrm{mM}$ EDTA as MDH inhibitors and $20 \mathrm{mM}$ sodium formate supplied for reducing power regeneration, $13.2 \mathrm{mM}$ methanol was produced in the batch reaction at $25^{\circ} \mathrm{C}$ for $12 \mathrm{~h}$. In the case of the repeated-batch mode, a productivity of $2.17 \mu \mathrm{mol}$ methanol $/ \mathrm{h} / \mathrm{mg}$ cell was obtained for $24 \mathrm{~h}$ with three $8 \mathrm{~h}$ cycles [24]. Recently, more than $1.12 \mathrm{~g} / 1$ methanol was accumulated with $60 \%$ conversion using $17 \mathrm{~g}$ dry cell/1 of M. trichosporium $\mathrm{OB} 3 \mathrm{~b}$ in the presence of $400 \mathrm{mmol} / \mathrm{l}$ phosphate buffer, $10 \mathrm{mmol} / 1 \mathrm{MgCl}_{2}$, and $20 \mathrm{mmol} / 1$ sodium formate [11]. In addition, $0.95 \mathrm{~g} / 1$ methanol accumulated in a membrane-aerated reactor when methane and oxygen were introduced from two separate sources through dense silicone tubing.

In addition to methanotrophs, ammonia-oxidizing bacteria such as Nitrosomonas europaea and Nitrosococcus oceani have been shown to convert methane to methanol using ammonia monooxygenase (AMO). Although the substrate for AMO is ammonia, methane can be selectively and partially oxidized to methanol owing to the broad substrate specificity of AMO $[3,19,21]$. Similar to methanotrophs, the growth rate of ammonia-oxidizing bacteria is slow, and thus volumetric culture productivity is also low. One advantage of ammonia-oxidizing bacteria for methanol production is that it is difficult to further metabolize methanol owing to the absence of relevant enzymes, resulting in an accumulation of methanol in the medium. In order to maintain the metabolic activity of AMO, ammonia needs to be supplied as a growth substrate. Recently, mixed nitrifying enrichment cultures were used for methane-to-methanol conversion. Using a fed-batch reactor, $59.9 \mathrm{mg}$ methanol (expressed in 
COD) $/ 1$ was produced for $7 \mathrm{~h}$ with a maximum specific rate of $0.82 \mathrm{mg}$ methanol $\mathrm{COD} / \mathrm{mg}$ biomass COD. Thus, partial oxidation of methane to methanol by AOB may be an alternative to methanotroph-mediated conversion [53].

\section{Concluding Remarks and Future Prospects}

To date, unsuccessful heterologous MMO expression in E. coli is the primary obstruction for the industrial application of methane-to-methanol conversion. Thus, the development of a recombinant $\mathrm{MMO}$ enzyme is a prerequisite to enzyme-based bioconversion of methane to methanol. A higher productivity of methane to methanol will require the molecular engineering of MMO for enhanced activity, which will become more feasible as our understanding of the structure and catalytic mechanism of MMO improves. Although $\mathrm{MMO}$ is an efficient enzyme for methane oxidation under mild reaction conditions, regeneration of the reducing power such as NADH for efficient utilization of molecular oxygen for the monooxidation of methane is a barrier to the commercialization of $\mathrm{MMO}$-catalyzing methane oxidation reactions. Regeneration of the reducing agent using an electrochemical method in the presence of an enzyme biocatalyst can be a solution. The molecular engineering of other monooxygenases such as P450 to accept methane as a substrate is yet another possible solution for efficient methane conversion to methanol, since P450 monooxygenase can be heterologously expressed in E. coli.

Metabolically engineered methanotrophs for enhanced methane-to-methanol productivity have not yet been constructed since genetic tools for methanotroph engineering are limited. At present, wild-type methanotrophic cellbased methane-to-methanol conversion is limited by slow growth rates and poor specific and volumetric productivities in the range of $\mu \mathrm{mol} / \mathrm{mg} \cdot \mathrm{h}$. To achieve higher rates of methane-to-methanol conversion, efficient methods for methanol accumulation and reducing power regeneration need to be developed by redesigning the metabolic pathway using metabolic engineering and synthetic biology approaches. Indeed, the reconstruction of the methanotroph metabolic network will likely be a key approach for the development of a microbial cell factory to produce a variety of chemicals from methane. In addition, the circumvention of product inhibition will be required in cases where methanol is accumulated at high concentrations. The screening of novel methanotrophs using omics-based approaches is another possible tool for identifying higher methane utilizers. Lastly, methane mass transfer needs to be enhanced for higher productivity.

The market demand for methanol is continuously increasing owing to its versatility in chemical synthesis. Thus, methanebased methanol can be considered as a drop-in item that can be readily commercialized upon development of a costeffective biocatalytic method of methane-to-methanol conversion in the near future. The cost of methanol production from methane will be competitive owing to methane abundance, especially with the recent boom in shale gas production. In addition, methanol transformation using biocatalytic conversion methods may be especially applicable to countries with small-scale gas fields and poor infrastructure, owing to the low capital investment of the bioprocess for methane-to-methanol conversion compared with existing indirect chemical methods and the flexibility of biocatalytic methane-to-methanol processes.

In conclusion, the development of efficient biocatalytic methane-to-methanol conversion methods will play a key role in the commercialization of methane reforming, and the production of a variety of chemicals from methanol has the potential to replace the petroleum-based production of chemicals. The commercial success of biocatalytic methaneto-methanol conversion may be a starting point for a paradigm shift from petroleum-based chemical refineries to gas-based refineries.

\section{Acknowledgments}

This work was supported by the New \& Renewable Energy Core Technology Program of the Korea Institute of Energy Technology Evaluation and Planning (KETEP) and a grant from the Ministry of Trade, Industry \& Energy, Republic of Korea (No. 20133030000090). This work was also supported by the Sogang University Research Grant of 2014 (SRF-201414001).

\section{References}

1. Anthony C. 2004. The quinoprotein dehydrogenases for methanol and glucose. Arch. Biochem. Biophys. 428: 2-9.

2. Alvarez-Galvan MC, Mota N, Ojeda M, Rojas S, Navarro RM, Fierro JLG. 2011. Direct methane conversion routes to chemicals and fuels. Catal. Today 171: 15-23.

3. Arp DJ, Sayavedra-Soto LA, Hommes NG. 2002. Molecular biology and biochemistry of ammonia oxidation by Nitrosomonas europaea. Arch. Microbiol. 178: 250-255.

4. Balasubramanian R, Rosenzweig AC. 2007. Structural and mechanistic insights into methane oxidation by particulate methane monooxygenase. Acc. Chem. Res. 40: 573-580.

5. Benlounes O, Mansouri S, Rabia C, Hocine S. 2008. Direct 
oxidation of methane to oxygenates over heteropolyanions. J. Nat. Gas Chem. 17: 309-312.

6. Bollinger Jr JM. 2010. Getting the metal right. Nature 465: 40-41.

7. Chistoserdova L, Lidstrom ME. 2013. Aerobic methylotrophic prokaryotes, pp. 267-285. In DeLong EF, Lory S, Stackebrandt E, Thompson F, Rosenberg E (eds.). The Prokaryotes. Springer, Berlin-Heidelberg.

8. Conrado RJ, Gonzalez R. 2014. Envisioning the bioconversion of methane to liquid fuels. Science 343: 621-623.

9. Culpepper MA, Rosenzweig AC. 2012. Architecture and active site of particulate methane monooxygenase. Crit. Rev. Biochem. Mol. Biol. 47: 483-492.

10. DiSpirito AA, Kunz RC, Choi DW, Zahn JA. 2004. Respiration in methanotrophs, pp. 149-168. In Zannoni D (eds.). Respiration in Archaea and Bacteria: Diversity of Procaryotic Respiratory Systems. Springer, Netherlands, Dordrecht.

11. Duan C, Luo M, Xing X. 2011. High-rate conversion of methane to methanol by Methylosinus trichosporium OB3b. Bioresour. Technol. 102: 7349-7353.

12. Dunfield PF, Yuryev A, Senin P, Smirnova AV, Stott MB, Hou S, et al. 2007. Methane oxidation by an extremely acidophilic bacterium of the phylum Verrucomicrobia. Nature 450: $879-882$.

13. Friedle S, Reisner E, Lippard SJ. 2010. Current challenges of modeling diiron enzyme active sites for dioxygen activation by biomimetic synthetic complexes. Chem. Soc. Rev. 39: 2768-2779.

14. Furuto T, Takeguchi M, Okura I. 1999. Semicontinuous methanol biosynthesis by Methylosinus trichosporium OB3b. J. Mol. Catal. A Chem. 144: 257-261.

15. Gesser HD, Hunter NR, Prakash CB. 1985. The direct conversion of methane to methanol by controlled oxidation. Chem. Rev. 85: 235-244.

16. Gunaseelan VN. 1997. Anaerobic digestion of biomass for methane production: a review. Biomass Bioenerg. 13: 83-114.

17. Hakemian S, Rosenzweig AC. 2007. The biochemistry of methane oxidation. Annu. Rev. Biochem. 76: 223-241.

18. Hammond C, Forde MM, Rahim MHA, Thetford A, He Q, Jenkins RL, et al. 2012. Direct catalytic conversion of methane to methanol in an aqueous medium by using Copper-Promoted Fe-ZSM-5. Angew. Chem. Int. Ed. 51: 5129-5133.

19. Holmes AJ, Costello A, Lidstrom ME, Murrell JC. 1995. Evidence that particulate methane monooxygenase and ammonia monooxygenase may be evolutionarily related. FEMS Microbiol. Lett. 132: 203-208.

20. Hwang JW, Choi YB, Park S, Choi CY, Lee EY. 2007. Development and mathematical modeling of a two-stage reactor system for trichloroethylene degradation using Methylosinus trichosporium OB3b. Biodegradation 18: 91-101.

21. Hyman MR, Murton IB, Arp DJ. 1988. Interaction of ammonia monooxygenase from Nitrosomonas europaea with alkanes, alkenes, and alkynes. Appl. Environ. Microbiol. 54: 3187-3190.

22. Kang J, Lee EY, Park S. 2001. Co-metabolic biodegradation of trichloroethylene by Methylosinus trichosporium is stimulated by low concentrations of methane or methanol. Biotechnol. Lett. 23: 1877-1882.

23. Khadem AF, Pol A, Wieczorek A, Mohammadi SS, Francoijs $\mathrm{KJ}$, Stunnenberg HG, et al. 2011. Autotrophic methanotrophy in Verrucomicrobia: Methylacidiphilum fumariolicum SolV uses the Calvin-Benson-Bassham cycle for carbon dioxide fixation. J. Bacteriol. 193: 4438-4446.

24. Kim HG, Han GH, Kim SW. 2010. Optimization of lab scale methanol production by Methylosinus trichosporium OB3b. Biotechnol. Bioprocess Eng. 15: 476-480.

25. Kim HG, Kim SW. 2006. Purification and characterization of a methanol dehydrogenase derived from Methylomicrobium sp. HG-1 cultivated using a compulsory circulation diffusion system. Biotechnol. Bioprocess Eng. 11: 134-139.

26. Kuuskraa VA, Stevens SH, Moodhe KD. 2013. Technically Recoverable Shale Oil and Shale Gas Resources: An Assessment of 137 Shale Formations in 41 Countries Outside the United States, pp. 1-730. US Department of Energy, Washington, DC.

27. Lee EY, Ye BD, Park SH. 2003. Development and operation of a trickling biofilter system for continuous treatment of gas-phase trichloroethylene. Biotechnol. Lett. 25: 1757-1761.

28. Lee SG, Goo JH, Kim HG, Oh JI, Kim YM, Kim SW. 2004. Optimization of methanol biosynthesis from methane using Methylosinus trichosporium OB3b. Biotechnol. Lett. 26: 947-950.

29. Lee SJ, McCormick MS, Lippard SJ, Cho US. 2013. Control of substrate access to the active site in methane monooxygenase. Nature 494: 380-384.

30. Lieberman RL, Rosenzweig AC. 2004. Biological methane oxidation: regulation, biochemistry, and active site structure of particulate methane monooxygenase. Crit. Rev. Biochem. Mol. Biol. 39: 147-164.

31. Lipscomb JD. 1994. Biochemistry of the soluble methane monooxygenase. Annu. Rev. Microbiol. 48: 371-399.

32. Li T, Wang SJ, Yu CS, Ma YC, Li KL, Lin LW. 2011. Direct conversion of methane to methanol over nano- $\left[\mathrm{Au} / \mathrm{SiO}_{2}\right]$ in [Bmim]Cl ionic liquid. Appl. Catal. A Gen. 398: 150-154.

33. Marilyn R. 2011. Worldwide look at reserves and production. Oil Gas J. 109: 26-29.

34. Matsen JB, Yang S, Stein LY, Beck D, Kalyuzhnaya MG. 2013. Global molecular analyses of methane metabolism in methanotrophic alphaproteobacterium, Methylosinus trichosporium OB3b. Part I: transcriptomic study. Front. Microbiol. 4: 1-16.

35. Muehlhofer M, Strassner T, Herrmann WA. 2002. New catalyst systems for the catalytic conversion of methane into methanol. Angew. Chem. Int. Ed. 41: 1745-1747.

36. Murrell JC, McDonald IR, Gilbert B. 2000. Regulation of expression of methane monooxygenases by copper ions. Trends Microbiol. 8: 221-225.

37. Murrell JC, Smith TJ. 2010. Biochemistry and molecular biology of methane monooxygenase, pp. 1046-1055. In Timmis KN (ed.). Handbook of Hydrocarbon and Lipid Microbiology (eds.). Springer-Verlag. 
38. Nielsen AK, Gerdes K, Degn H, Murrel JC. 1996. Regulation of bacterial methane oxidation: transcription of the soluble methane mono-oxygenase operon of Methylococcus capsulatus (Bath) is repressed by copper ions. Soc. Gen. Microbiol. 142: 1289-1296.

39. Olah GA. 2005. Beyond oil and gas: the methanol economy. Angew. Chem. 44: 2636-2639.

40. Park D, Lee J. 2013. Biological conversion of methane to methanol. Kor. J. Chem. Eng. 30: 977-987.

41. Pellegrini LA, Soave G, Gamba S, Langè S. 2011. Economic analysis of a combined energy-methanol production plant. Appl. Energ. 88: 4891-4897.

42. Periana RA, Taube DJ, Evitt ER, Loffler DG, Wentrcek PR, Voss G, Masuda T. 1993. A mercury-catalyzed, high-yield system for the oxidation of methane to methanol. Science 259: 340-343.

43. Pol A, Heijmans K, Harhangi HR, Tedesco D, Jetten MSM, Camp HJMOD. 2007. Methanotrophy below pH 1 by a new Verrucomicrobia species. Nature 450: 874-878.

44. Prior SD, Dalton H. 1985. The effect of copper ions on membrane content and methane monooxygenase activity in methanol-grown cells of Methylococcus capsulatus (Bath). J. Gen. Microbiol. 131: 155-163.

45. Pulver S, Froland WA, Fox BG, Lipscomb JD, Solomon EI. 1993. Spectroscopic studies of the coupled binuclear non-heme iron active site in the fully reduced hydroxylase component of methane monooxygenase: comparison to deoxy and deoxy-azide hemerythrin. J. Am. Chem. Soc. 115: 12409-12422.

46. Reinhold VN. 1992. Methane conversion by oxidative processes. In Wolf EE (ed.). Fundamental and Engineering Aspects. Van Nostrand Reinhold, New York.

47. Rosenzweig AC, Brandstetter H, Whittington DA, Nordlund P, Lippard SJ, Frederick CA. 1997. Crystal structures of the methane monooxygenase hydroxylase from Methylococcus capsulatus (Bath): implications for substrate gating and component interactions. Protein Struct. Funct. Genet. 29: 141-152.

48. Schrader J, Schilling M, Holtmann D, Sell D, Filho MV, Marx A, Vorholt JA. 2008. Methanol-based industrial biotechnology: current status and future perspectives of methylotrophic bacteria. Trends Biotechnol. 27: 107-115.

49. Semrau JD, DiSpirito AA, Yoon S. 2010. Methanotrophs and copper. FEMS Microbiol. Rev. 34: 496-531.

50. Shilov AE, Shul'pin GB. 1997. Activation of $\mathrm{CH}$ bonds by metal complexes. Chem. Rev. 97: 2879-2932.

51. Shindell D, Kuylenstierna JCI, Vignati E, Dingenen RV, Amann M, Klimont Z, et al. 2012. Simultaneously mitigating near-term climate change and improving human health and food security. Science 335: 183-189.

52. Stirling DI, Dalton H. 1978. Purification and properties of an NAD $(\mathrm{P})^{+}$-linked formaldehyde dehydrogenase from Methylococcus capsulatus (Bath). J. Gen. Appl. Microbiol. 107: 19-29.

53. Taher E, Chandran K. 2013. High-rate, high-yield production of methanol by ammonia-oxidizing bacteria. Environ. Sci. Technol. 47: 3167-3173.

54. Takeguchi M, Furuto T, Sugimori D, Okura I. 1997. Optimization of methanol biosynthesis by Methylosinus trichosporium OB3b: an approach to improve methanol accumulation. Appl. Biochem. Biotechnol. 68: 143-152.

55. Takeguchi M, Okura I. 2000. Role of iron and copper in particulate methane monooxygenase of Methylosinus trichosporium OB3b. Catal. Surv. Jap. 4: 51-63.

56. Trotsenko YA, Murrell JC. 2008. Metabolic aspects of aerobic obligate methanotrophy. Adv. Appl. Microbiol. 63: 183-229.

57. Ward N, Larsen O, Sakwa J, Bruseth L, Khouri H, Durkin AS, et al. 2004. Genomic insights into methanotrophy: the complete genome sequence of Methylococcus capsulatus (Bath). Plos Biol. 2: 1616-1628.

58. Wood DA, Nwaoha C, Towler BF. 2012. Gas-to-liquids (GTL): a review of an industry offering several routes for monetizing natural gas. J. Nat. Gas Sci. Eng. 9: 196-208.

59. Xin JY, Cui JR, Niu JZ, Hua SF, Xia CG, Li SB, Zhu LM. 2004. Production of methanol from methane by methanotrophic bacteria. Biocatal. Biotransform. 22: 225-229.

60. Xin JY, Cui JR, Hu XX, Li SB, Xia CG, Zhu LM, Wang YQ. 2002. Particulate methane monooxygenase from Methylosinus trichosporium is a copper-containing enzyme. Biochem. Biophys. Res. Commun. 295: 182-186.

61. Yoshizawa K, Shiota Y. 2006. Conversion of methane to methanol at the mononuclear and dinuclear copper sites of particulate methane monooxygenase (pMMO): a DFT and QM/MM study. J. Am. Chem. Soc. 128: 9873-9881.

62. Zahn JA, Bergmann DJ, Boyd JM, Kunz RC, DiSpirito AA. 2001. Membrane-associated quinoprotein formaldehyde dehydrogenase from Methylococcus capsulatus Bath. J. Bacteriol. 183: $6832-6840$. 